\title{
INFLUENCE OF DYSPROSIUM ON THE DIELECTRIC PROPERTIES OF BISMUTH LAYERED STRUCTURED PIEZOCERAMICS
}

\author{
G. Rajashekhar ${ }^{1}$, T. Sreekanth ${ }^{2}$, Y. Aparna ${ }^{3}$ and P. Sarah ${ }^{1 *}$ \\ ${ }^{1}$ Department of Physics Vardhaman College of Engineering, \\ Shamshabad-501218, (Telangana State) India \\ ${ }^{2}$ Department of Physics JNTUH College of Engineering, Nachupally, \\ Jagtial-505501, (Telangana State) India \\ ${ }^{3}$ Department of Physics Jawaharlal Nehru Technological University, \\ Hyderabad-500085 (Telangana State) India \\ "E-mail: p.sarah@vardhaman.org
}

\begin{abstract}
Piezoelectric ceramics are used for the applications of piezoelectric sensors, actuators and transducers. Bismuth Layered Structured Ferroelectric (BLSFs), a member of the Aurivillius family, has been studied for its application in FeRAMs (non-volatile Ferroelectric Random Access Memory). Besides the above usage, BLSFs also have their functions in electronics such as high-temperature sensors, resonators and other similar devices. In regards to its application as resonators, piezoelectric materials are used as inductors since BLSFs have higher operating temperatures as compared to lead-based materials such as PZT. Therefore BLSFs are ideal alternatives to PZT kind of lead-based materials for piezoelectric applications such as sensors at high temperatures. $\mathrm{SrBi}_{4} \mathrm{Ti}_{4} \mathrm{O}_{15}$ (SBT) compounds, a four-layered member of the family of Aurivillius BLSFs are rare earth modified materials prepared by adding Dysprosium in A site $\left(\mathrm{Sr}_{0.2} \mathrm{Na}_{0.4} \mathrm{Dy}_{0.4} \mathrm{Bi}_{4} \mathrm{Ti}_{4} \mathrm{O}_{15}\right)$ (SNDBT). They are prepared by a conventional double sintering method using planetary wet Ball Milling. XRD revealed the formation of a single phase with an orthorhombic structure. Scanning Electron Microscopy (SEM) is used for sample microstructure and grain size studies. The dielectric loss and dielectric constant at various temperatures and frequencies are studied.
\end{abstract}

Keywords: Piezoelectric, Bismuth Layered Structured Ferroelectrics (BLSFs), Curie temperature, dielectric constant

() RASĀYAN. All rights reserved

\section{INTRODUCTION}

$\mathrm{SrBi}_{4} \mathrm{Ti}_{4} \mathrm{O}_{15}$ (SBT) is one of the examples of the BLSF family. The general formula of BLSF is $\left(\mathrm{Bi}_{2} \mathrm{O}_{2}\right)^{2+}\left(\mathrm{A}_{\mathrm{m}-1} \mathrm{~B}_{\mathrm{m}} \mathrm{O}_{3 \mathrm{ml}+1}\right)^{2-}$, here $\left(\mathrm{A}_{\mathrm{m}-1} \mathrm{~B}_{\mathrm{m}} \mathrm{O}_{3 \mathrm{ml}+1}\right)^{2-}$ is the perovskite layers and $\mathrm{m}$ denoting a number perovskite layers and $\mathrm{A}$ take place monovalent, divalent, trivalent ions , B takes place a $\mathrm{Ti}^{+4}$ tetravalent, $\mathrm{Nb}^{+5}$ pentavalent and $\mathrm{W}^{+6}$ hexavalent ions ${ }^{1-3}$. Their high transition temperature or Curie temperatures and low dielectric loss make BLSFs quantitatively usable. SBT has four perovskites of the same form $\mathrm{TiO}_{6}$ (octahedral) cells sandwiched in between $\left(\mathrm{Bi}_{2} \mathrm{O}_{2}\right)^{2+}$ layers. The compound possesses orthorhombic symmetry and the space group of the compound is $\mathrm{A} 2{ }_{1} \mathrm{am}^{4}$.

The changes in its different properties by the addition of oxides of rare-earths into another oxide compound are obviously understood with regard to the change in ionic radii. In electro-ceramic materials, for example, PZT (Lead Zirconate Titanate), the adding of a rare earth ion which maybe off-valent (e.g. $\mathrm{La}^{3+}$ ) it observed affect of its electrical in that way physical properties. A few PZT doped with La (PLZT) structure has produced ceramic materials with excessive density and appropriate clearness, making them appropriate in order to electro-optic applications ${ }^{5}$. It is found that in $\mathrm{Bi}_{4} \mathrm{Ti}_{3} \mathrm{O}_{12}(\mathrm{BIT})$ and $\mathrm{SrBi}_{4} \mathrm{Ti}_{4} \mathrm{O}_{15}$ (SBT) doped with $\mathrm{La}, \mathrm{Sr}^{2+}$ ions, that are greater stable act as $\mathrm{La}^{3+}$ and accordingly decreasing

Rasayan J. Chem., 12(1), 324-328(2019)

http://dx.doi.org/10.31788/RJC.2019.1213032

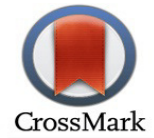


the acceptability of $\mathrm{La}^{3+}$ into perovskite layers. The presence of $\mathrm{Sr}^{2+}$ ion at the A site of $\mathrm{SrBi}_{4} \mathrm{Ti}_{4} \mathrm{O}_{15}$, can also result in the blending of $\mathrm{Dy} 3^{+}$into the $\mathrm{Bi}_{2} \mathrm{O}_{2}$ layers at low doping contents. For non-lead electroceramics, Yamaji et.al ${ }^{6}$ has investigated the impact of doping Dy in $\mathrm{BaTiO}_{3}$. It is discovered that in doped ceramics, the common grain sizes of are smaller, wherein as the dielectric constants are greatly that of un doped $\mathrm{BaTiO}_{3}$ higher than an extensive variety of temperatures ${ }^{7-10}$. This paper reports the Microstructure Dielectric constant, Curie temperature and Dielectric loss of the substitution of $\mathrm{Na}^{+1}$ and $\mathrm{Dy}^{+3}$ in place of $\mathrm{Sr}^{+2}$ in SBT.

\section{EXPERIMENTAL}

SNDBT ceramics are prepared from commercially available carbonates of Strontium and Sodium, oxides of Dy, Bi and Ti (Sigma Aldrich) using the solid state double sintering technique. The chemical ratios as per stoichiometry are accurately weighed and grounded by way of planetary wet ball mill in distilled water medium for $5 \mathrm{~h}$. The mixture is next calcined at $800 \mid{ }^{\circ} \mathrm{C}$ up to 2 hours. ${ }^{11-12}$. The calcined chemical is once more grounded up to $5 \mathrm{~h}$. Then pellets are cast using a hydraulic press of $10 \mathrm{Mpa}$ pressure by adding $1 \%$ PVA (polyvinyl alcohol) as if binder. The thickness of the pellet is $0.1 \mathrm{~cm}$ and $1.10 \mathrm{~cm}$ diameter and final sintering temperature are around $1150^{\circ} \mathrm{C}$ for about $2 \mathrm{~h}$. The density of the pellet is estimated using the Archimedes principle. Using XRD (X-Ray Diffraction) (Philips X-pert PRO). The sintered powder is evaluated for its crystalline properties. The microstructure was found through a Scanning Electron Microscope (Carl ZEISS EVO18). Conductive gold paint is coated on both sides of the material and the dielectric loss and dielectric constant as if the function of frequency from room temperature to up to $700^{\circ} \mathrm{C}$ is measured using Wayne-Kerr 6500P high-frequency LCR meter.

\section{XRD Studies}

\section{RESULTS AND DISCUSSION}

SNDBT ceramic diffraction patterns matched with standard $\mathrm{SrBi}_{4} \mathrm{Ti}_{4} \mathrm{O}_{15}$ phase with a slight shift in peaks. Single phase form with a orthorhombic structure is determined by XRD (Fig.-1).

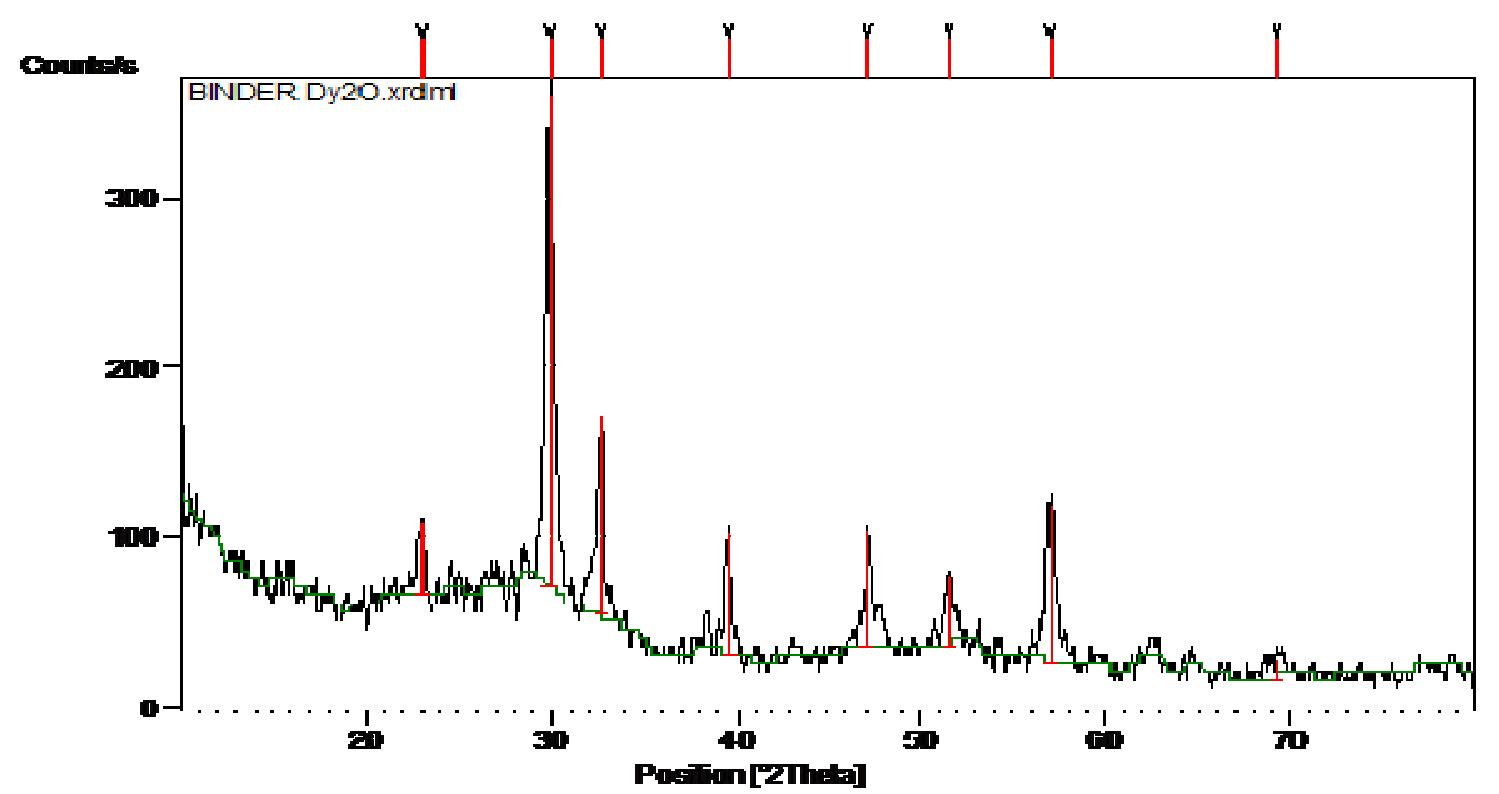

Fig.-1: The X-ray Diffraction Pattern of SNDBT Ceramics

\section{Scanning Electron Microscopy Studies}

Figure-2 is given the SEM micrograph of the fractured surface of SBT and SNDBT ceramics. Plate-like grains with grain sizes between 100 and $200 \mathrm{~nm}$ is observed. All samples possess a relatively dense structure. The samples have plate-like grains in random orientations. SEM pictures reveal that the compound ceramics has a good density.

The densities are calculated by the liquid displacement method based on the Archimedes principle. Distilled water is used as liquid media. Experimental density of $7.194 \mathrm{~g} / \mathrm{cm}^{3}$ is obtained. 
RASĀYAN J. Chem.

Vol. 12 | No. 1 |324 - 328| January - March | 2019
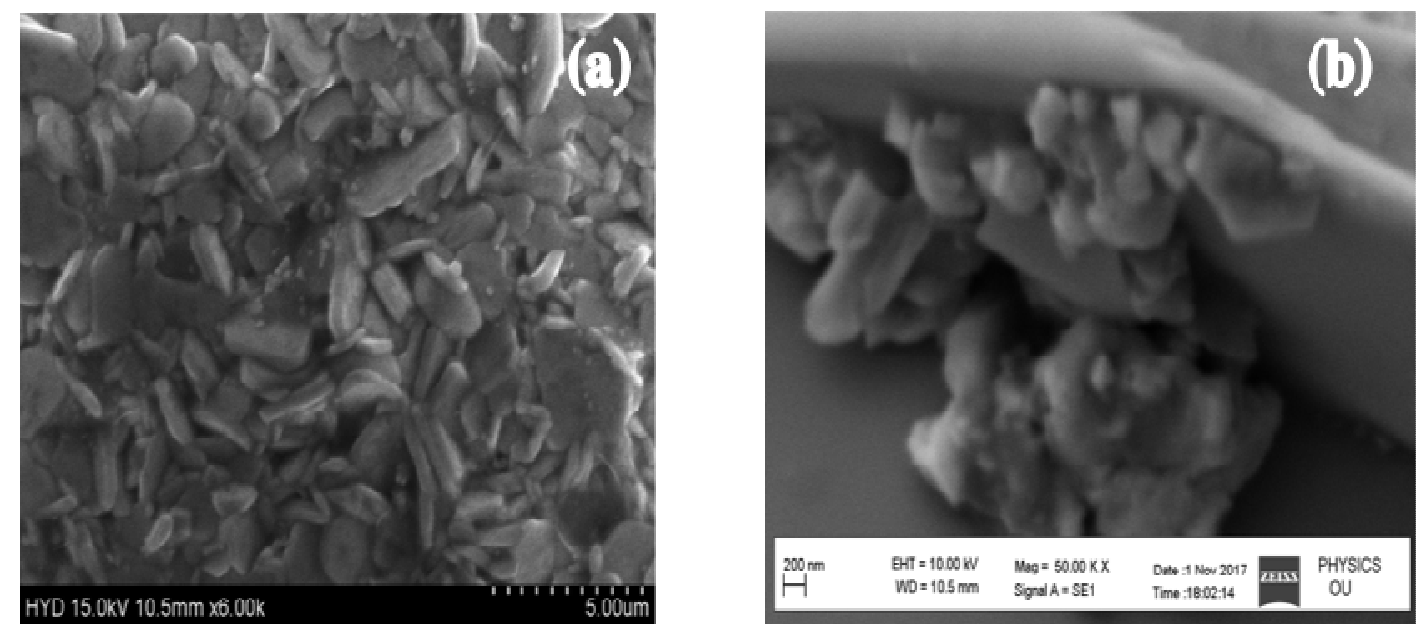

Fig.-2: SEM Images of (a) Pure SBT and (b) Dy-Doped SNDBT

\section{Dielectric Properties}

The dielectric constant of SNDBT ceramic as if the function of both temperature and frequencies (1 kHz and $1 \mathrm{MHz}$ ) is shown in Fig.-3. It can be seen as the dielectric constant value is increasing like the temperature increases and frequency decreases. A strong peak is observed at $671^{\circ} \mathrm{C}$ at all frequencies. This consistent with Curie temperature, $\mathrm{T}_{\mathrm{c}}$. For $\mathrm{SrBi}_{4} \mathrm{Ti}_{4} \mathrm{O}_{15}$ (without any dopants), the Curie temperature is $535^{\circ} \mathrm{C}^{13-14}$. With the substitution of $\mathrm{Na}^{+1}$ Sodium and $\mathrm{Dy}^{+3}$ Dysprosium in place of Strontium, the Curie temperature was found to increase. The dielectric constant values at various frequencies are given in table1. The increased $T_{c}$ confirms the distortion of Oxygen octahedral. The $T_{c}$ depends on ionic displacements. This ionic displacement depends on ionic polarizability, ionic size, and tolerance factor. The degree of distortion can be evaluated by a tolerance factor $(\mathrm{t}){ }^{15}$. According to the Goldsmith relation $^{14}$, the tolerance factor $(\mathrm{t})$ is:

$\mathrm{t}=\mathrm{R}_{\mathrm{A}}+\mathrm{R}_{\mathrm{O}} / \sqrt{\sqrt{2}}\left(\mathrm{R}_{\mathrm{B}}+\mathrm{R}_{\mathrm{O}}\right)(1)$

Where, $R_{A}$ is ionic radii of $A$-site ions and $R_{B}$ is ionic radii of $B$ - Site ions. The tolerance factor value (t) generally lies between 0 and 1 .

The ionic radius of oxygen is denoted by $\mathrm{R}_{\mathrm{O}}$. The tolerance factor of pure SBT is 0.938 . With the substitution of $\mathrm{Dy}^{3+}$, the tolerance factor reduced. According to the theory of Donaji $i^{16}$, there is an increase in the Curie temperature with a decrease in tolerance. Figure-3 shows the dielectric loss of $\mathrm{Sr}_{0.2} \mathrm{Na}_{0.4} \mathrm{Dy}_{0.4} \mathrm{Bi}_{4} \mathrm{Ti}_{4} \mathrm{O}_{15}$ ceramic as a function of temperature at various frequencies $(1 \mathrm{kHz}-1 \mathrm{MHz})$.

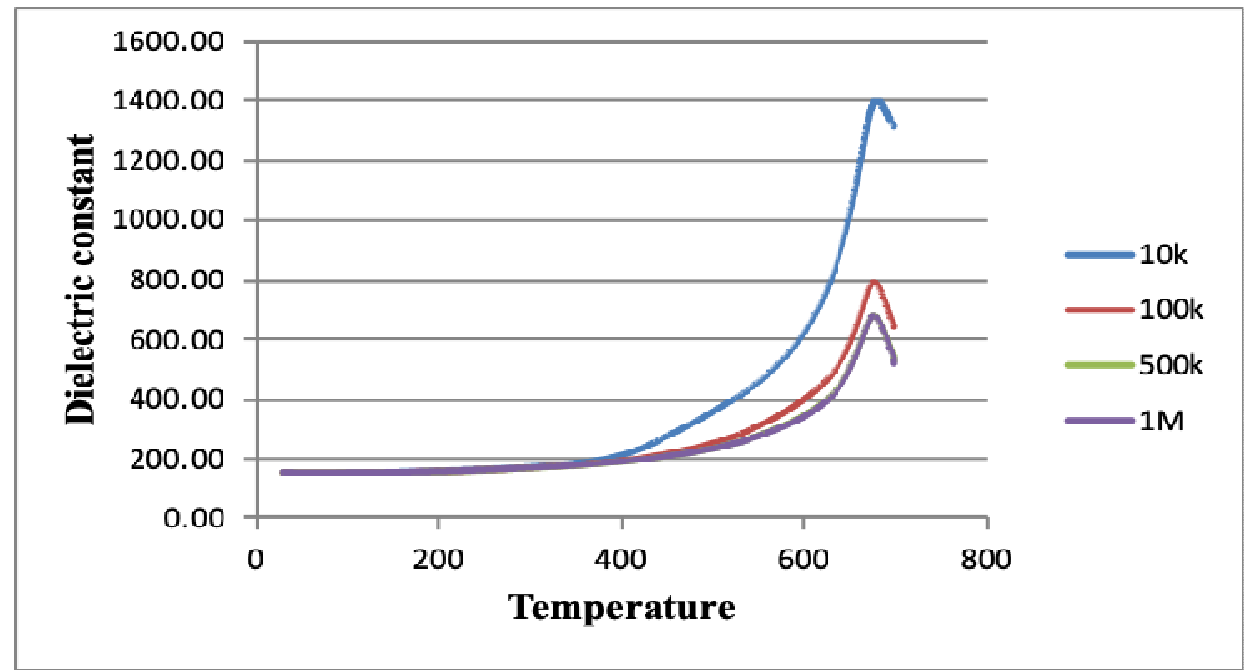

Fig.-3: Dielectric Constant $(\mathcal{E})$ of SNDBT as a Function of Temperature at Different Frequencies 326 
RASĀYAN J. Chem.

Vol. 12 | No. 1 |324 - 328| January - March | 2019

Table-1: Dielectric Constant at Different Frequencies

\begin{tabular}{c|c|c|c|c|c|c|c}
\hline S. No. & Sample & \multicolumn{2}{|c|}{ Dielectric Constant at RT } & \multicolumn{2}{|c|}{ Dielectric Constant at $\mathrm{T}_{\mathrm{c}}$} & \multirow{2}{*}{$\mathrm{T}_{\mathrm{c}}$} & $\begin{array}{c}\text { Dielectric } \\
\text { loss }\end{array}$ \\
\cline { 3 - 6 } & & At $10 \mathrm{kHz}$ & At $100 \mathrm{kHz}$ & At $10 \mathrm{kHz}$ & At $100 \mathrm{kHz}$ & & \\
\hline 1 & SBT & 234 & 234 & 2668 & 1971 & 535 & 0.021 \\
\hline 2 & SNDBT & 160 & 160 & 1390 & 785 & 676 & 0.013 \\
\hline
\end{tabular}

The temperature and frequency dependent dielectric loss of SBT modified with Dysprosium is shown in Fig.-4. There is a slight decrease in the dielectric loss with the introduction of Dysprosium in SBT ceramics. The reduction is attributed to the cationic vacancies that are formed which in turn suppress the oxygen vacancy formation. This further leads to a reduction in space charges. Thus a lower dielectric loss of doped SBT ceramics is observed ${ }^{17,18}$. The dielectric loss is very low, almost nearing zero till $400^{\circ} \mathrm{C}$. With temperature increasing beyond $400^{\circ} \mathrm{C}$, the dielectric loss increased.

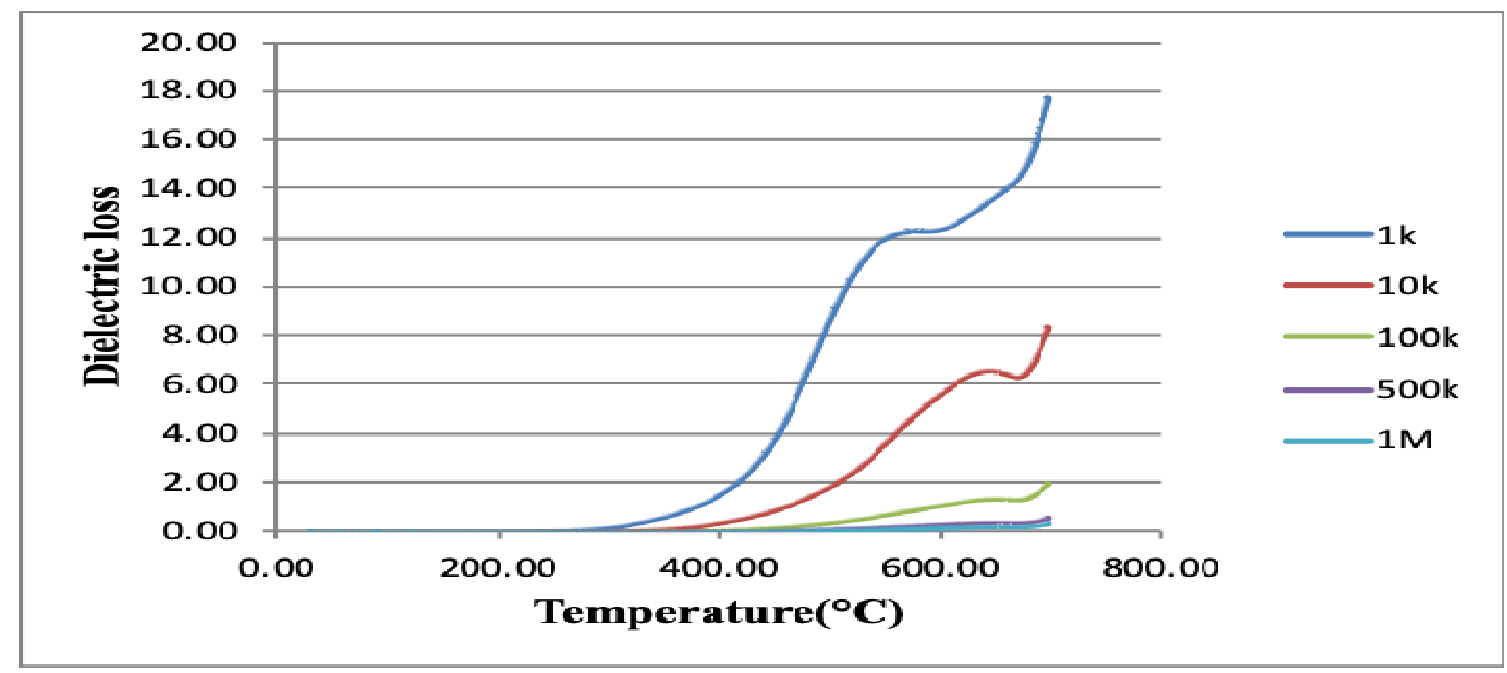

Fig.-4: Dielectric Loss as a Function of Temperature for SNDBT Ceramic

\section{CONCLUSION}

Polycrystalline $\mathrm{Sr}_{0.2} \mathrm{Na}_{0.4} \mathrm{Dy}_{0.4} \mathrm{Bi}_{4} \mathrm{Ti}_{4} \mathrm{O}_{15}$ ceramic pellets are synthesized following the solid state sintering technique by using planetary wet ball mill. Single Phase is formed which is confirmed by XRD. Curie temperature increased from $535^{\circ} \mathrm{C}$ for pure SBT to $671^{\circ} \mathrm{C}$ with modification of $\mathrm{Na}^{2+}$ and $\mathrm{Dy}^{3+}$ doping. The dielectric constant is 1350 at $10 \mathrm{kHz}$ at the observed Curie temperature. The results obtained indicate that the as-synthesized materials are excellent ceramics for piezoelectric applications.

\section{ACKNOWLEDGMENT}

The authors acknowledge the Science \& Engineering Board (SERB) for the financial support and the management of Vardhaman College of Engineering for their constant encouragement and support.

\section{REFERENCES}

1. M.V. Gelfuso, J. Am. Ceram. Soc., 82, 2368(1999), DOI: 10.1063/1.3068344

2. T Ogawa, J. Eur. Ceram. Soc., 24, 1517(2004), DOI: 10.1016/S0955-2219(03)00527-2

3. B. Mamatha, M.B Suresh, A.R James, M. Vithal, and P. Sarah, Phys. Scr., 84, 055704 (2011), DOI: 10.1088/0031-8949/84/05/055704

4. C. H. Hervoches, A. Snedden, R. Riggs, S. H. Kilcoyne, J. Solid State Chem., 164, 280(2002), DOI: $10.1006 /$ jssc.2001.9473 
RASĀYAN J. Chem.

Vol. 12 | No. 1 |324 - 328| January - March | 2019

5. G. H. Haertling and C.E. Land, J. Am. Ceram. Soc., 54, 1(1971), DOI: 10.1111/j.11512916.1970.tb12105.X-i1

6. A. Yamaji, Y. Enomoto, K. Kinoshita and T. Murakami, J. Am. Ceram. Soc., 60, 97(1977), DOI: $10.1111 / \mathrm{j} .1151-2916.1977 . t b 15479 . x$

7. Rizwana and P. Sarah, Ferroelectrics., 467, 181(2014),DOI:10.1080/00150193.2014.932616

8. Gagan Anand, Satya Krishna Nippani, Piyush Kuchhal, Ajay Vasishth and P. Sarah, Ferroelectrics., 516(1) , 36(2017), DOI: 10.1081/00150193.2017.1362277

9. Rizwana, T Radha Krishna, A.R James, P Sarah, Crystal Research and Technology., 42 (7),699(2007), DOI: 10.1002/crat.200610891

10. B Mamatha, P Sarah, Ferroelectrics., 482, 90(2015),DOI: 10.1080/00150193.2015.1057071

11. G. Rajashehar, Rizwana and P. Sarah, Rasayan Journal of Chemistry.,11,1(2018), DOI: 10.7324/RJC.2018.1112057

12. B. Mamatha, A. R. James, and P. Sarah, Physica B: Condensed Matter., 405,4772(2010), DOI: $10.1016 /$ j.physb.2010.08.074

13. CanJin, Chen-PengDu, Jun Zhu, Jun-huiHe, Xiang-yu Mao and Xiao-bing Chen, Phys. D: Appl.Phys., 39,2415(2006), DOI: 10.1021/acs.chemrev.5b00703

14. B. Mamatha, K. Ashok, A. R. James, and P. Sarah , Phys. Scr., 85,65705(2012), DOI: 10.1088/0031-8949/85/06/065705

15. M. Itoh and H. Taniguchi., Ferroelectrics., 369,127(2008), DOI: $10.1080 / 00150190802377918$

16. D. Y. Suarez and I. M. Reaney, J. Mater. Res., 16,31(2001), DOI: 10.1557/JMR.2001.0433

17. Y. Noguchi, M.Miyayama, Appl.Phys.Let.,78(5), 1903( 2001), DOI: 10.1143/JJAP.41.7062

18. Y Wu, SJ Limmer, TP Chou C Nguyen, J. Mater. Sci. Let, 21, 947(2002), DOI: 10.1023/A:101607772442721

[RJC-3032/2018] 